\title{
Seven-hydroxy-2-(4-hydroxy-3-methoxyphenyl)-chromen-4- one reduces atherogenic index and Nrf2 and GPx gene expressions in hyperlipidemic rats
}

\author{
Prasetyastuti $^{1 *}$, Rahmah Dara Ayunda ${ }^{2}$, Sunarti $^{1}$ \\ ${ }^{1}$ Faculty of Medicine, Public Health and Nursing, ${ }^{2}$ Biomedical Science, Faculty of Medicine, Public Health and Nursing, \\ Universitas Gadjah Mada, Yogyakarta, Indonesia
}

*For correspondence: Email: prasetyastuti.djati@gmail.com; Tel: +62-81227882379

\begin{abstract}
Purpose: To investigate the effect of 7-hydroxy-2-(4-hydroxy-3-methoxyphenyl)-chromen-4-one isolated from mahogany (Swietenia macrophylla King) seeds on atherogenic index, expressions of nuclear factor erythroid 2-related factor 2 (Nrf2) and expression of the glutathione peroxidase (GPX) genes in hyperlipidemic rats.

Methods: A total of 25 rats male aged 8 weeks and weighing an average of $200 \mathrm{~g}$ were used. They were divided into five groups as follows: (I) normal (N), (II) hyperlipidemic (HL), (III) hyperlipidemic rats treated with simvastatin ( $H L+S V)$, (IV and V) hyperlipidemic rats treated with 30 or $90 \mathrm{mg}$, respectively, of 7-hydroxy-2-(4-hydroxy-3-methoxyphenyl)-chromen-4-one per $200 \mathrm{~g}$ body weight per day for 4 weeks. Atherogenic index (AI) was calculated from the levels of triglyceride (TG) and high-density lipoprotein (HDL) while Nrf2 and GPx gene expressions were determined by quantitative real-time polymerase chain reaction ( $q R T-P C R)$.

Results: Two different doses of 7-hydroxy-2-(4-hydroxy-3-methoxyphenyl)-chromen-4-one in hyperlipidemic rats significantly reduced their atherogenic index $(p<0.05)$. Nrf2 and GPx expression levels were lower than ( $p>0.05)$ those of hyperlipidemic group.

Conclusion: Seven-hydroxy-2-(4-hydroxy-3-methoxyphenyl)-chromen-4-one reduces the atherogenic index and expression levels of Nrf2 and GPx genes in hyperlipidemic rats. Thus, this compound has potential as an antihyperlipidemic agent
\end{abstract}

Keywords: Hyperlipidemia, Oxidative stress, Nrf2, GPx, Gene expression

\begin{abstract}
This is an Open Access article that uses a fund-ing model which does not charge readers or their institutions for access and distributed under the terms of the Creative Commons Attribution License (http://creativecommons.org/licenses/by/4.0) and the Budapest Open Access Initiative (http://www.budapestopenaccessinitiative.org/read), which permit unrestricted use, distribution, and reproduction in any medium, provided the original work is properly credited.

Tropical Journal of Pharmaceutical Research is indexed by Science Citation Index (SciSearch), Scopus, International Pharmaceutical Abstract, Chemical Abstracts, Embase, Index Copernicus, EBSCO, African Index Medicus, JournalSeek, Journal Citation Reports/Science Edition, Directory of Open Access Journals (DOAJ), African Journal Online, Bioline International, Open-J-Gate and Pharmacy Abstracts
\end{abstract}

\section{INTRODUCTION}

Hyperlipidemia, a form of dyslipidemia, is a lipid metabolism disorder characterized by increased levels of cholesterol and/or triglycerides. Hyperlipidemia is caused by many factors, including an unhealthy lifestyle, low physical activity, and a high-fat diet [1].

Oxidative stress causes translocation of the nuclear factor erythroid 2-related factor 2 (Nrf2) from the cytoplasm to the nucleus, where it combines with the antioxidant-responsive 
element (ARE) and induces the expression of antioxidant genes such as superoxide dismutase $(S O D)$ and glutathione peroxidase (GPX) [2]. Nrf2 is a regulator of oxidative stress in the cytoplasm and is removed by Kelch-like $\mathrm{ECH}$-associated protein 1 (Keap1) for proteosomal degradation $[3,4]$. Keap1 regulates the expression of Nrf2 and enzymes involved in the Nrf2-Keap1 downstream signaling pathway, such as GPx. In hyperoxic conditions, the conformation of the Keap1 protein is changed and its binding to Nrf2 is prevented. Then, Nrf2 expression is increased, which also increases the expression of downstream antioxidants and resistance to oxidative damage [5].

Oxidative stress can be prevented by endogenous and exogenous antioxidants. Endogenous antioxidants protect cells from damage caused by oxidative stress. In hyperlipidemia, endogenous antioxidants are not sufficient to prevent cell damage. Therefore, exogenous antioxidants are needed to protect cells from oxidative stress-related diseases.

Many studies have reported that flavonoid compounds reduce oxidative stress. A previous study found that 7-hydroxy-2-(4-hydroxy-3methoxyphenyl)-chromen-4-one isolated from mahogany seeds (Swietenia macrophylla King) influences the expression of some genes involved in carbohydrate metabolism in a rat Type 2 diabetes mellitus (T2DM) model [6]. This study aimed to evaluate the effects of 7-hydroxy2-(4-hydroxy-3-methoxyphenyl)-chromen-4-one flavonoid groups on the atherogenic index and expression of Nrf2 and GPx genes in hyperlipidemic rats.

\section{EXPERIMENTAL}

\section{Animals}

Twenty-five male rats (Rattus norvegicus), aged 8 weeks old, with an average weight of $200 \mathrm{~g}$, were obtained from the Center for Food and Nutrition Studies, Universitas Gadjah Mada, Yogyakarta, Indonesia. The rats were housed in individual cages and acclimatized to laboratory conditions $\left(22-25^{\circ} \mathrm{C}\right)$ and a 12-h daylight cycle for 7 days with free access to food and water. The standard diet was AIN $93 \mathrm{M}$ consisting of (g/kg): casein $24 \%$, DL-methionine $0.30 \%$, corn starch $61 \%$, vitamin mixture $1 \%$, mineral mixture $3.5 \%$, and choline chloride $0.2 \%$, with $5 \%$ alpha cells and $5 \%$ corn oil. This study was approved by the Health and Medical Research Ethics Committee of the Faculty of Medicine, Public Health and Nursing, Universitas Gadjah Mada, Yogyakarta, Indonesia (approval
no.KE/FK/0729/EC/2018) and was conducted in accordance with the guidelines of Declaration of Helsinki issued in 1964 and amended in 1996 [7]

\section{Experimental design}

Twenty-five rats were divided into five groups: normal $(\mathrm{N})$, hyperlipidemic (HL), hyperlipidemic rats treated with simvastatin $(\mathrm{HL}+\mathrm{SV})$, hyperlipidemic rats treated with 30 or $90 \mathrm{mg} 7-$ hydroxy-2-(4-hydroxy-3-methoxyphenyl)chromen -4-one per $200 \mathrm{~g}$ body weight per day $(\mathrm{HL}+30$ or $\mathrm{HL}+90$, respectively). The drugs were administered orally by gavage for 4 weeks.

\section{Atherogenic index measurement}

Assay kits for serum triglyceride (TG) and highdensity lipoprotein (HDL) were purchased from Dyasis ${ }^{\circledR}$ (Holzheim, Germany). The atherogenic index (AI) was calculated using the following equation: $\mathrm{Al}=\log (\mathrm{TG} / \mathrm{HDL})[8]$.

\section{Gene expression analysis using quantitative polymerase chain reaction (qPCR)}

The cDNAs were synthesized using the iScript cDNA Synthesis kit (Bio-Rad) according to the manufacturer's protocol. The SsoFast ${ }^{\mathrm{TM}}$ Evagreen® Supermix (Bio-Rad) was used for qPCR on an iCycler Model CFX 96 Real-Time System (Bio-Rad). The qPCR reaction was conducted for each gene (Nrf2 and GPx) using the same internal control Beta actin gene (Table 1). The program for cDNA amplification was 5 min at $95^{\circ} \mathrm{C}$, followed by 40 cycles at $95^{\circ} \mathrm{C}$ for 60 sec, and $57^{\circ} \mathrm{C}$ for $60 \mathrm{sec}$.

Table 1: Primer sequences for cDNA amplification

\begin{tabular}{ll}
\hline Nrf2 & F 5'-GCCTTCCTCTGCTGCCATTAGTC-3' \\
& R 5'-GTGCCTTCAGTGTGCTTCTGGTT-3' \\
\hline GPx & F5'-GCTGCTCATTGAGAATGTCG-3' \\
& R 5'-GAATCTCTTCATTCTTGCCATT-3' \\
\hline Beta & F 5'-ACGGTCAGGTCATCACTATCG- 3' \\
actin & R 5'- GGCATAGAGGTCTTTACGGATG-3' \\
\hline
\end{tabular}

\section{Statistical analysis}

The results are expressed as mean \pm standard deviation (SD). Differences in atherogenic indices among the groups before and after treatment with 30 or 90mg 7-hydroxy-2-(4hydroxy-3-methoxyphenyl)-chromen-4-one per $200 \mathrm{~g}$ body weight per day $(\mathrm{HL}+30$ or $\mathrm{HL}+90$, respectively) were analyzed by one-way ANOVA followed by the Games-Howell test. The expression levels of liver Nrf2 and GPX genes after treatment were compared by one-way ANOVA followed by the Games-Howell tests. Paired $t$-tests were used to analyze the 
atherogenic index before and after treatment. Differences were considered significant at $p<0.05$.

\section{RESULTS}

After 4 weeks of daily administration of 30 or 90mg of 7-hydroxy-2-(4-hydroxy-3methoxyphenyl)-chromen-4-one per $200 \mathrm{~g}$ body weight, serum triglyceride levels decreased significantly $(p<0.05)$. The results are shown in Table 2. As shown in Table 3, HDL levels increased significantly $\quad(p<0.05) \quad$ after administration of 30 or $90 \mathrm{mg}$ of 7-hydroxy-2-(4hydroxy-3-methoxyphenyl)-chromen-4-one per $200 \mathrm{~g}$ body weight per day for 4 weeks.

Administration of 30 or $90 \mathrm{mg}$ of 7-hydroxy-2-(4hydroxy-3-methoxyphenyl)-chromen-4-one per $200 \mathrm{~g}$ body weight per day for 4 weeks significantly reduced the atherogenic index $(p<0.05)$. The greatest decline was observed in the group treated with $90 \mathrm{mg}$ of 7-hydroxy-2-(4hydroxy-3-methoxyphenyl)-chromen-4-one per $200 \mathrm{~g}$ body weight (Table 4).

Administration of 30 or $90 \mathrm{mg}$ of 7-hydroxy-2-(4hydroxy-3-methoxyphenyl)-chromen-4-one per $200 \mathrm{~g}$ body weight per day for 4 weeks significantly reduced the relative gene expression levels of Nrf2 in rat liver tissue ( $p>0.05$, Figure 1).

Administration of 30 or $90 \mathrm{mg}$ of 7-hydroxy-2-(4hydroxy-3-methoxyphenyl)-chromen-4-one per $200 \mathrm{~g}$ body weight per day for 4 weeks significantly reduced the relative gene expression levels of GPX in rat liver tissue ( $p>0.05$, Figure 2).

\section{DISCUSSION}

This study showed that administration of 30 or 90mg of 7-hydroxy-2-(4-hydroxy-3methoxyphenyl)-chromen-4-one per $200 \mathrm{~g}$ body weight per day for 4 weeks lowered the levels of triglycerides, increased HDL levels, and reduced the atherogenic index $(p<0.05)$. Based on these results, we conclude that 7-hydroxy-2-(4hydroxy-3-methoxyphenyl)-chromen-4-one has the potential to treat dyslipidemia.

Mallick and Khan [9] reported that sweet oranges (Citrus sinensis) and grapefruit (Citrus paradisi) produce antioxidants that have hypolipidemic effects in rats fed with a cholesterol-rich diet. Another study showed that chrysin flavonoid from honey, propolis, and plant extracts exerted

Table 2: Effect of 7-hydroxy-2-(4-hydroxy-3-methoxyphenyl)-chromen-4-one on serum triglyceride levels (mg/dL) in a hyperlipidemic rat

\begin{tabular}{|c|c|c|c|c|}
\hline \multirow[t]{2}{*}{ Group } & \multicolumn{2}{|c|}{ Mean $(\mathrm{mg} / \mathrm{dL}) \pm \mathrm{SD}$} & \multirow[t]{2}{*}{ Mean difference $(95 \% \mathrm{Cl})$} & \multirow[t]{2}{*}{$P$-value } \\
\hline & Before & After & & \\
\hline Normal & $67.47 \pm 2.75$ & $68.12 \pm 2.41$ & $-0.65(-1.07 ;-0.23)$ & 0.013 \\
\hline Hyperlipidemic & $135.97 \pm 9.49$ & $138.05 \pm 9.02$ & $-2.08(-3.85 ;-0.30)$ & 0.031 \\
\hline$H L+S V$ & $132.88 \pm 5.55$ & $79.25 \pm 3.04$ & 53.63 (43.25; 64.01) & 0.000 \\
\hline $\mathrm{HL}+30$ & $126.52 \pm 7.86$ & $92.78 \pm 3.13$ & 33.74 (21.85; 45.64) & 0.001 \\
\hline $\mathrm{HL}+90$ & $133.05 \pm 7.60$ & $86.17 \pm 3.04$ & $46.88(38.91 ; 54.85)$ & 0.000 \\
\hline
\end{tabular}

Table 3: Effect of 7-hydroxy-2-(4-hydroxy-3-methoxyphenyl)-chromen-4-one on HDL levels (mg/dL) in a hyperlipidemic rats

\begin{tabular}{|c|c|c|c|c|}
\hline \multirow[t]{2}{*}{ Group } & \multicolumn{2}{|c|}{ Mean $(\mathrm{mg} / \mathrm{dL}) \pm \mathrm{SD}$} & \multirow{2}{*}{$\begin{array}{c}\text { Mean difference } \\
(95 \% \mathrm{Cl})\end{array}$} & \multirow[t]{2}{*}{$P$-value } \\
\hline & Before & After & & \\
\hline Normal & $73.63 \pm 2.46$ & $75.21 \pm 2.92$ & $-1.58(-3.03 ;-0.13)$ & 0.039 \\
\hline Hyperlipidemic & $24.25 \pm 2.69$ & $23.32 \pm 2.86$ & $0.93(0.35 ; 1.50)$ & 0.011 \\
\hline $\mathrm{HL}+\mathrm{SV}$ & $25.48 \pm 2.83$ & $61.31 \pm 3.73$ & $-35.83(-42.14 ;-29.52)$ & 0.000 \\
\hline $\mathrm{HL}+30$ & $27.08 \pm 2.04$ & $46.79 \pm 1.86$ & $-19.72(-23.20 ;-16.23)$ & 0.000 \\
\hline$H L+90$ & $26.37 \pm 3.83$ & $55.44 \pm 1.85$ & $-29.07(-35.24 ;-22.91)$ & 0.000 \\
\hline
\end{tabular}

Table 4: Effect of 7-hydroxy-2-(4-hydroxy-3-methoxyphenyl)-chromen-4-one on atherogenic index in a hyperlipidemic rat

\begin{tabular}{lcccc}
\hline Group & \multicolumn{2}{c}{ Atherogenic index } & Mean difference (95\%Cl) & $\boldsymbol{P}$-value \\
& Before & After & & \\
\hline Normal & $-0.04 \pm 0.023$ & $-0.04 \pm 0.018$ & $0.005(-0.006 ; 0.016)$ & 0.269 \\
Hyperlipidemic & $0.75 \pm 0.070$ & $0.77 \pm 0.070$ & $-0.024(-0.036 ;-0.011)$ & 0.006 \\
HL + SV & $0.72 \pm 0.057$ & $0.11 \pm 0.037$ & $0.607(0.507 ; 0.707)$ & 0.000 \\
HL + 30 & $0.67 \pm 0.030$ & $0.30 \pm 0.010$ & $0.373(0.340 ; 0.406)$ & 0.000 \\
HL +90 & $0.71 \pm 0.091$ & $0.19 \pm 0.003$ & $0.515(0.402 ; 0.628)$ & 0.000 \\
\hline
\end{tabular}




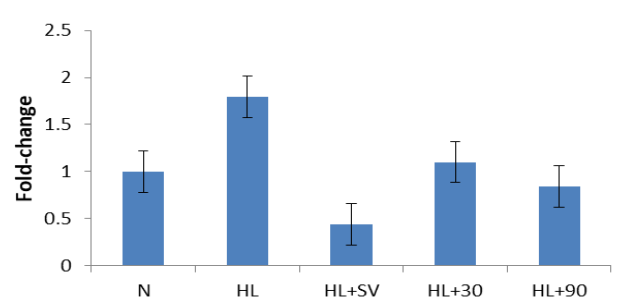

Figure 1: Nrf2 relative expression level. $\mathrm{N}$, normal rats; HL, hyperlipidemic rats; $H L+S V$, hyperlipidemic rats+simvastatin; $\mathrm{HL}+30$, hyperlipidemic rats $+30 \mathrm{mg}$ of 7-hydroxy-2-(4-hydroxy-3-methoxyphenyl)-chromen-4one; and $\mathrm{HL}+90$, hyperlipidemic rats $+90 \mathrm{mg}$ of $7-$ hydroxy-2-(4-hydroxy-3-methoxyphenyl)-chromen-4one

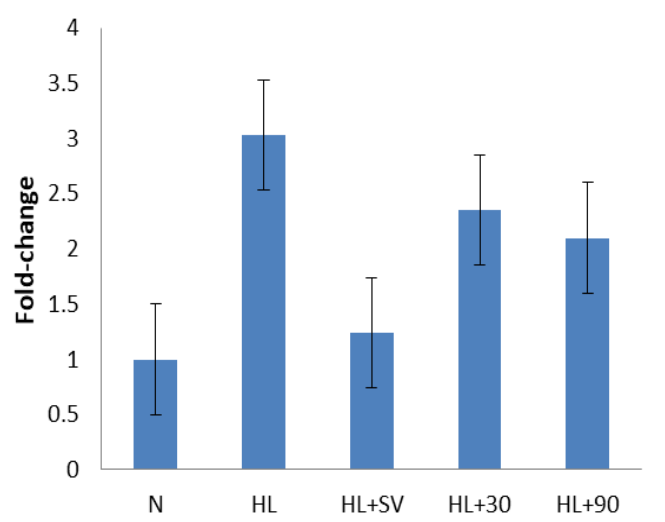

Figure 2: GPx relative expression levels. $\mathrm{N}$, normal rats; HL, hyperlipidemic rats; $H L+S V$, hyperlipidemic rats+simvastatin; $\mathrm{HL}+30$, hyperlipidemic rats $+30 \mathrm{mg}$ of 7-hydroxy-2-(4-hydroxy-3-methoxyphenyl)-chromen-4one; and $\mathrm{HL}+90$, hyperlipidemic rats $+90 \mathrm{mg}$ of $7-$ hydroxy-2-(4-hydroxy-3-methoxyphenyl)-chromen-4one

antioxidant and hypolipidemic effects on Triton WR-1339-induced hyperlipidemia in female C57BL/6 mice [10]. Zeni et al. [11] reported that black mulberry (Morus nigra) leaf extracts contained abundant polyphenols, particularly chlorogenic acid. Chlorogenic acid had beneficial effects by reducing cholesterol and controlling fatty accumulations in the liver by increasing peroxisome proliferator-activated receptor alpha $($ PPAR- $\alpha)$ [12].

In the present study, rats with dyslipidemia had higher Nrf2 expression levels than normal rats, and treatment with 7-hydroxy-2-(4-hydroxy-3methoxyphenyl)-chromen-4-one isolated from mahogany (Swietenia macrophylla King) seeds reduced the Nrf2 expression levels. These results suggest that 7-hydroxy-2-(4-hydroxy-3methoxyphenyl)-chromen-4-one has antioxidant properties that reduce dyslipidemia-induced oxidative stress. Polyphenolic compounds and antioxidant activity also were detected in extracts of white (Morus alba) and black (Morus nigra) mulberry leaf [13-15].

GPx is localized in the cytoplasm, in the mitochondrial matrix, and in insoluble forms associated with membranes involved in the neutralization of lipid hydroperoxides [16]. The GPx function is responsible for lowering hydrogen peroxide $\left(\mathrm{H}_{2} \mathrm{O}_{2}\right)$ levels and converting lipoperoxides and organic hydroperoxides into suitable hydroxylation compounds, which are less reactive. Quercetin has in vivo antioxidant properties, and quercetin treatment increases hepatic GPx expression in older rats [17]. Research by Martin et al [18] showed that cocoa polyphenolic extract was an effective inducer of GPx. These reports are consistent with the study of Phachonpai et al [19], which reported that quercetin added to rat diet significantly increased the superoxide dismutase (SOD), catalase (CAT), and GPx activities [19,20].

\section{CONCLUSION}

The results of this study indicate that 7-hydroxy2-(4-hydroxy-3-methoxyphenyl)-chromen-4-one lowers the atherogenic index and expression levels of Nrf2 and GPx genes in hyperlipidemic rats, and there may be suitable for management of hyperlipidemia but further investigations are required to ascertain this.

\section{DECLARATIONS}

\section{Acknowledgement}

This study was supported by the Community Funds from Faculty of Medicine, Public Health, and Nursing, Universitas Gadjah Mada, Yogyakarta, Indonesia.

\section{Conflict of interest}

No conflict of interest is associated with this study.

\section{Contribution of authors}

We declare that this work was done by the authors named in this article and all liabilities pertaining to claims relating to the content of this article will be borne by the authors". All authors read and approved the manuscript for publication.

\section{Open Access}

This is an Open Access article that uses a funding model which does not charge readers or their institutions for access and distributed under the 
terms of the Creative Commons Attribution License (http://creativecommons.org/licenses/by/ 4.0) and the Budapest Open Access Initiative (http://www.budapestopenaccessinitiative.org/rea d), which permit unrestricted use, distribution, and reproduction in any medium, provided the original work is properly credited.

\section{REFERENCES}

1. Liu C, Lin JD. PGC-1 Coactivators in the control of energy metabolism. Acta Biochim Biophys Sin 2011; 43(4): 248-257.

2. Klaassen $C D$, Reisman $S A$. Nrf2 the rescue: effects of the antioxidative/electrophilic response on the liver. Toxicol. Appl. Pharmacol 2010; 244(1): 57-65.

3. Ma Q. Role of nrf2 in oxidative stress and toxicity. Annu. Rev. Pharmacol. Toxicol 2013; 53: 401-426

4. Itoh $K$, Ishii $T$, Wakabayashi $N$, Yamamoto M. Regulatory mechanisms of cellular response to oxidative stress. Free Radic Res 1999; 31: 319-324.

5. Danielli NM, Trevisan R, Mello DF, Fischer $K$, Deconto VS, da Silva Acosta D, Bianchini A, Bainy ACD, Dafre AL. Upregulating Nrf2-dependent antioxidant defenses in Pacific oysters Crassostrea gigas: Investigating the Nrf2/Keap1 pathway in bivalves. Comp Biochem Physiol C Toxicol Pharmacol. 2017; Part C $195: 16-26$

6. Prasetyastuti, Sunarti, Sadewa AH, Mustofa. Effect of 7hydroxy-2-(4-hydroxy-3-methoxy-phenyl)- chroman-4one (Swietenia Macrophylla KING seed) on Retinol Binding Protein-4 and Phosphoenolpyruvate Carboxykinase gene Expression in Type 2 Diabetic rats. Rom J Diabetes Nutr Metab Dis 2016; 23(3): 255-265.

7. World Health Organization. Declaration of Helsinki. Br Med J 1996; 313(7070): 1448-1449.

8. Dobiasova M, Frohlich J. The plasma parameter log (TG/HDL-C) as an atherogenic index: correlation with lipoprotein particle size and esterification rate in apoBlipoprotein-depleted plasma (FER(HDL). Clin Biochem 2001; 34(7): 583-588

9. Mallick N, Khan RA. Antihyperlipidemic effects of Citrus sinensis, Citrus paradisi, and their combinations. I Pharm Bioallied Sci 2016; 8(2): 112-118.

10. Zarzecki MS, Araujo SM, Bortolotto VC, De Paula MT, Jesse CR, Prigol M. Hypolipidemic action of chrysin on Triton WR-1339- induced hyperlipidemia in female C57BL/6 mice. Toxicol Rep 2014; 1: 200-208
11. Zeni ALB, Moreira TD, Dalmagro AP, Camargo A, Bini $L A$, Simionatto $E L$, Scharf DR. Evaluation of phenolic compounds and lipid-lowering effect of Morus nigra leaves extract. An Acad Bras Cienc 2017; 89(4): 28052815

12. Wan CW, Wong CN, Pin WK, Wong MH, Kwok CY, Chan RY, Yu PH, Chan SY. Chlorogenic acid exhibits cholesterol lowering and fatty liver attenuating properties by up-regulating the gene expression of PPAR- $\alpha$ in hypercholesterolemic rats induced with a highcholesterol diet. Phytother Res 2013; 27: 545-551.

13. Sánchez-Salcedo EM, Mena $P$, García-Viguera $C$, Hernández F, Martínez JJ. (Poly) phenolic compounds and antioxidant activity of white (Morus alba) and black (Morus nigra) mulberry leaves Their potential for new products rich in phytochemicals. J Funct Foods 2015; 18: 1039-1046.

14. Malhi TH, Qadir MI, Khan YH, Ali M. Hepatoprotective activity of aqueous methanolic extract of Morus nigra against paracetamol-induced hepatotoxicity in mice. Bangladesh J Pharmacol 2014; 9(1) 60-66.

15. Araújo CM, Lúcio KP, Silva ME, Isoldi MC, de Souza GH, Brandão GC, Schultz R, Costa DC. Morus nigra leaf extract improves glycemic response and redox in the liver of diabetic rats. Food Funct 2015; 6: 3490-3499.

16. Martinez-Hervas S, Fandos $M$, Real JT, Espinosa $O$, Chaves FJ, Saez GT, Salvador A, Cerdá C, Carmena R, Ascaso JF. Insulin resistance and oxidative stress in familial combined hyperlipidemia. Atherosclerosis. 2008; 199(2): 384-389.

17. Nassef N, Louka M, Habib H. Quercetin Flavonoid Has In Vivo Antioxidant Properties By Increasing Hepatic Expression of Gpx and Hepatic Gpx Enzyme Activity In Old Rats [Abstract]. Physiol 2013; 27(1). Supplement.

18. Martín MA, Serrano ABG; Sonia Ramos S, Pulido MI, Bravo L, Goya L. Cocoa flavonoids up-regulate antioxidant enzyme activity via the ERK1/2 pathway to protect against oxidative stress-induced apoptosis in HepG2 cells. J Nutr Biochem 2010; 21: 196 -205.

19. Phachonpai W, Wattanathorn J, Muchimapura S, TongUn $T$, Preechagoon D. Neuroprotective effect of quercetin encapsulated liposomes: A novel therapeutic strategy against Alzheimer's disease. Am J Appl Sci 2010; 7(4): 480- 485

20. Sriraksa N, Wattanathorn J, Muchimapura S, Tiamkao S, Brown $K$, Chaisiwamongkol K. Cognitive enhancing effect of quercetin in a rat model of Parkinson's disease induced by 6-hydroxydopamine. Evid Based Complement Alternat Med 2012; 2012: 1-9. 